\title{
Гидрохимический режим озера Комариное, Хибинский щелочной массив, Мурманская область
}

Даувальтер М.В. ${ }^{1}$, Даувальтер В.А. ${ }^{2}$

${ }^{1}$ Геологический институт КНЦ РАН, Anamumbl, dauvalter@geoksc.apatity.ru

${ }^{2}$ Институт проблем промышленной экологии Севера КНЦ PAH, Anamumbl, v.dauvalter@ksc.ru

Аннотация. Проведены многолетние мониторинговые исследования химического состава воды оз. Комариное с целью оценки качества поверхностных вод на территории разработки апатит-нефелинового месторождения Олений ручей. Выявлена четкая достоверная тенденция к увеличению величины рН воды, минерализации, содержания главных ионов, нитрат-иона $\mathrm{NO}_{3}{ }^{-}$в последние годы, а также ряда микроэлементов ( $\mathrm{Sr}, \mathrm{Cu}, \mathrm{Mo}, \mathrm{F})$, в несколько раз превышающие величину предельно допустимых концентраций вредных веществ для воды рыбохозяйственных водоемов.

Ключевые слова: апатит-нефелиновые месторождения, Хибины, качество вод, поверхностные воды.

\section{The hydrochemical regime of Lake Komarinoe, Khibiny Alkaline Massive, Murmansk Region}

\author{
Dauvalter M.V. ${ }^{1}$, Dauvalter V.A. ${ }^{2}$ \\ ${ }^{1}$ Geological Institute KSC RAS, Apatity, dauvalter@geoksc.apatity.ru \\ ${ }^{2}$ Institute of North Industrial Ecology Problems Kola SC RAS, Apatity,v.dauvalter@ksc.ru
}

\begin{abstract}
Long-term monitoring studies of the chemical composition of water of Lake Komarinoe have been carried out in order to assess the quality of surface water in the territory of the development of the Oleniy Ruchey apatite-nepheline deposit. A clear reliable tendency has been revealed to increase the $\mathrm{pH}$ value of water, mineralization, the content of basic ions, nitrate ion $\mathrm{NO}_{3}^{-}$in recent years, as well as a number of trace elements ( $\left.\mathrm{Sr}, \mathrm{Cu}, \mathrm{Mo}, \mathrm{F}\right)$, several times higher than the maximum permissible concentrations of harmful substances for water of fishery ponds.
\end{abstract}

Key words: apatite-nepheline deposits, Khibiny, water quality, surface water.

\section{Введение}

Горнодобывающая промышленность являются одним из наиболее мощных факторов антропогенного преобразования окружающей среды, в том числе природных вод. Качество природных вод на прилегающих территориях ухудшается в результате разработки месторождений полезных ископаемых. Последствия влияния техногенного воздействия горнодобывающих предприятий на природные воды обобщены в обзорных работах (Мироненко и др., 1988, 1989; Даувальтер, Кашулин, 2015). Изменения химического состава поверхностных вод обусловлены как поступлением загрязняющих веществ из поверхностных техногенных накопителей (пруды-отстойники, массивы отвальных пород и т.п.), так и нарушением естественного гидродинамического и гидрохимического режима поверхностных и подземных вод (Даувальтер, Даувальтер, 2019). В отработанных горных пространствах происходят процессы, увеличивающие минерализацию и изменяющие химический состав шахтных вод, которые выносят на поверхность соединения, являющиеся источниками загрязнения водных артерий, дренирующих как территорию месторождений, так и прилегающие к горнорудным предприятиям районы.

Акционерное общество «Северо-Западная Фосфорная Компания» (АО «СЗФК») учреждено ПАО «Акрон» в 2005 г. для реализации проекта по созданию новой фосфорной сырьевой базы в Мурманской области. В ноябре 2006 г. АО «СЗФК» получило лицензию на право пользования недрами месторождений апатит-нефелиновых руд Олений Ручей и Партомчорр. В 2012 г. завершено строительство первой очереди ГОК, выполнены пусконаладочные работы в корпусах обогатительной фабрики, получены первые тонны апатитового концентрата. С июня 2013 г. АО «СЗФК» полностью обеспечивает потребности российских химических предприятий группы «Акрон» в фосфатном сырье. Основным принципом экологической политики АО «СЗФК» является устойчивое раз- 
витие при максимально рациональном использовании природных ресурсов и сохранении благоприятной окружающей среды для будущих поколений. Компания проводит масштабную работу по исследованию негативных факторов действующего производства и их подавлению. Возможное воздействие на природоохранные объекты от эксплуатации промышленного предприятия сводится к минимуму (https://www.szfk.ru/).

Целью данной работы является оценка качества поверхностных вод на территории разработки апатит-нефелинового месторождения Олений ручей на примере оз. Комариное.

\section{Материалы и методы}

Химический состав воды оз. Комариное исследовался в период 2011-2019 гг. Пробы озерных вод отбирались сотрудниками $\mathrm{AO}$ «СЗФК» в среднем 4 раза в год. Анализ проб воды проводился в лаборатории ОАО КГИЛЦ: определялись значения $\mathrm{pH}$, жесткость, ионный состав $\left(\mathrm{Na}^{+}, \mathrm{K}^{+}, \mathrm{Ca}^{2+}\right.$, $\mathrm{Mg}^{2+}, \mathrm{NH}_{4}^{+}, \mathrm{HCO}_{3}^{-}, \mathrm{SO}_{4}^{2-}, \mathrm{Cl}^{-}, \mathrm{NO}_{3}^{-}, \mathrm{F}^{-}$), содержание микроэлементов ( $\mathrm{Al}, \mathrm{Fe}, \mathrm{Mn}, \mathrm{Sr}, \mathrm{Cu}, \mathrm{Zn}, \mathrm{Ni}, \mathrm{Co}$, $\mathrm{Cr}, \mathrm{Cd}, \mathrm{Pb}, \mathrm{Mo}, \mathrm{Hg}, \mathrm{B}, \mathrm{Be}, \mathrm{Ba})$. Проведен анализ изменения химического состава воды оз. Комариное до начала и за период разработки месторождения.

Озеро Комариное (водосбор р. Умба) расположено на юго-востоке Хибинского щелочного массива, в 8.9 км на северо-восток от пос. Коашва (Кашулин и др., 2012). Это небольшое (площадь 0.66 км$\left.^{2}\right)$, по форме близкое к овальной, озеро ледникового происхождения, наибольшая длина которого - 1.53 км, наибольшая ширина - 0.65 км, высота над уровнем моря 174 м. Территория водосборной площади по типу ландшафтов относится к лесотундровой зоне с высотами до 600 м. Берега озера высокие, каменистые. На водосборной площади распространены березовые и сосновые леса.

\section{Результаты и обсуждение}

До начала разработки месторождения Олений Ручей вода в оз. Комариное была нейтральной и характеризовалась невысокими значениями общей минерализации (в среднем 35.8 мг/л) и щелочности (в среднем 352 мкг-экв/л). Для озера были характерны низкие концентрации главных ионов, среди которых преобладают натрий (в среднем 6.55 мг/л) и гидрокарбонаты (в среднем 21.5 мг/л) (Кашулин и др., 2012).

Изменение гидрохимического состава воды оз. Комариное можно проследить по соотношению главных ионов, входящих в состав воды. До начала разработки месторождения формула ионного состава воды (Курлова) оз. Комариное выглядела следующим образом (Кашулин и др., 2012):

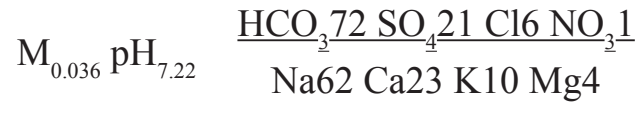

В 2011 г., т.е. в самом начале деятельности АО «СЗФК», формула Курлова воды оз. Комариное оставалась практически в неизменном виде:

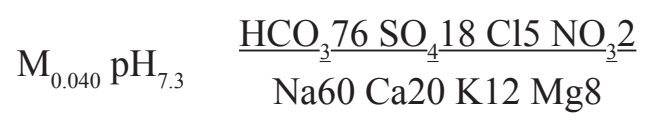

В 2019 г. эта формула претерпела значительные изменения:

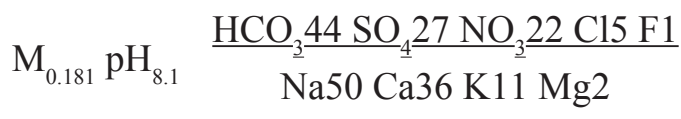

После начала деятельности АО «СЗФК» химический состав воды оз. Комариное значительно изменился. Растет содержание основных ионов, а вместе с ним увеличивается минерализация воды (рис. 1). Особенностью химического состава воды оз. Комариное, как и всех природных вод Хибинского щелочного массива (Даувальтер, Даувальтер, 2019), является повышенное относительное содержание катиона $\mathrm{K}^{+}$, которое сопоставимо по концентрациям с катионом $\mathrm{Ca}^{2+}$, тогда как природные воды равнинных территорий Мурманской области, не получающие прямое загрязнение промышленных предприятий, характеризуются гидрокарбонатным классом и кальциевой группой, и 
катион $\mathrm{K}^{+}$, как правило, находится на последнем месте среди основных катионов (Даувальтер, Даувальтер, 2010, 2014). За весь период гидрохимического мониторинга оз. Комариное отмечена достоверная тенденция увеличения содержания главных ионов и минерализации (рис. 1), что связано с добычей апатит-нефелиновых руд, выветриванием щелочных пород и поступлением его продуктов в природные воды. Гидрокарбонат-ион является преобладающим анионом в воде оз. Комариное, на втором месте стоит сульфат-ион, на третьем - нитрат-ион, который по содержанию в последнее время сопоставим с сульфат-ионом и намного превышает хлорид-ион (рис. 1), т.е. анионный состав воды оз. Комариное отличается от «классического» распределения, характерного для незагрязненных поверхностных вод Мурманской области (Даувальтер, Даувальтер, 2014). При добыче апатит-нефелиновых руд на АО «СЗФК» используют азотсодержащие взрывчатые вещества, которые значительно увеличивают содержание в поверхностных водах азотных соединений. Содержание нитрат-иона $\mathrm{NO}_{3}{ }^{-}$в последнее время растет в степенной прогрессии, как и главных ионов, достигая величины предельно допустимой концентрации для воды рыбохозяйственных водоемов ПДК

В воде оз. Комариное происходит достоверное увеличение величины $\mathrm{pH}$ за период наблюдений (рис. 2), что связано с усилением влияния разработки месторождения и увеличением глубины подземных горных выработок. В соответствии с требованиями к составу и свойствам воды водоемов рыбохозяйственного назначения, величина $\mathrm{pH}$ не должна выходить за пределы значений 6.5-8.5. В последнее время максимальные значения величины рН воды оз. Комариное приближаются к критическому значению 8.5 (рис. 2), которое по классификации величины $\mathrm{pH}$ соответствует граничному между слабощелочными и щелочными водами. Увеличение величины $\mathrm{pH}$ связано
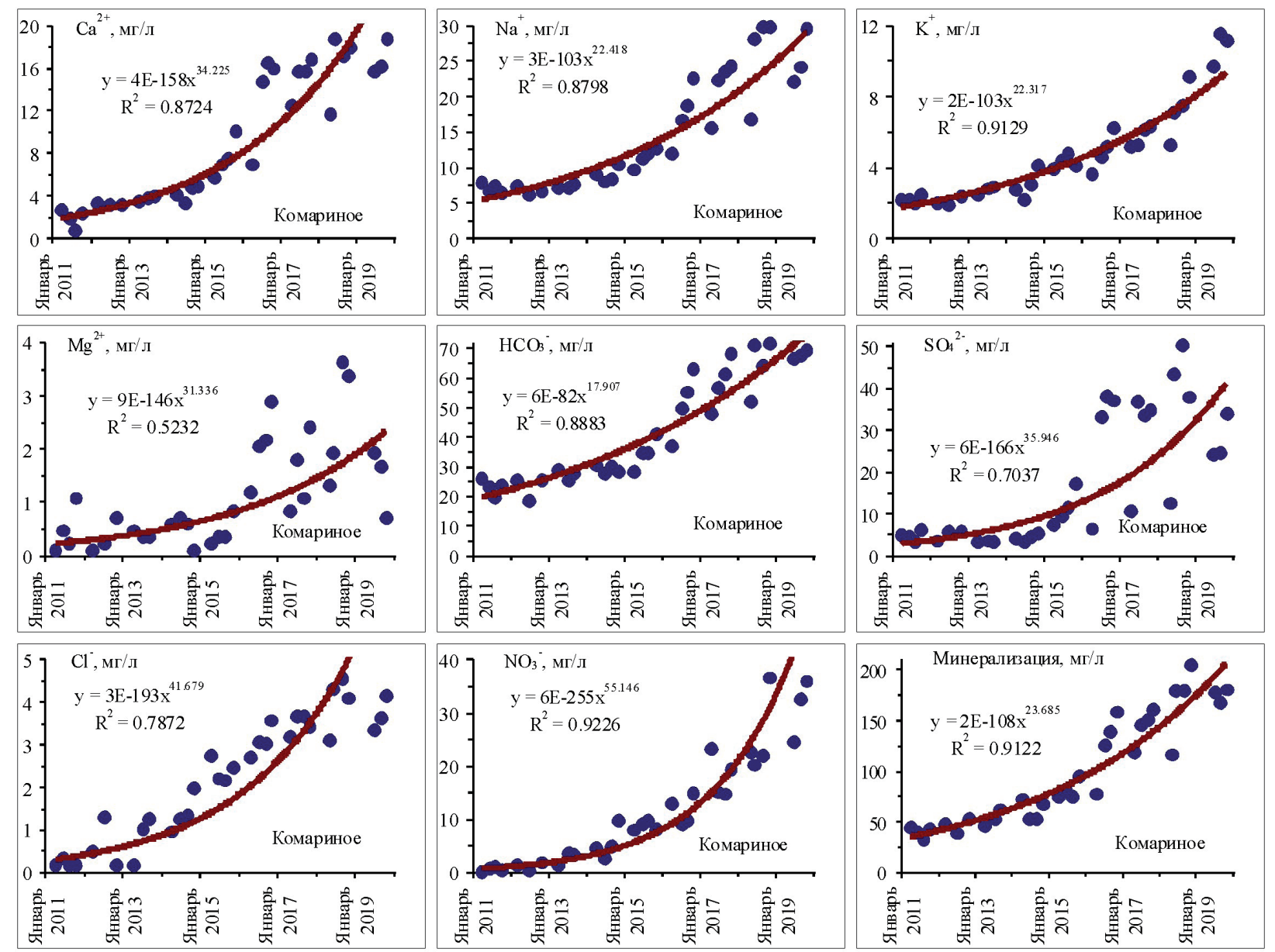

Рис. 1. Динамика основных ионов и минерализации воды оз. Комариное за 2011-2019 гг.

Fig. 1. Dynamics of basic ions and mineralization in the water of Lake Komarinoe for 2011-2019. 

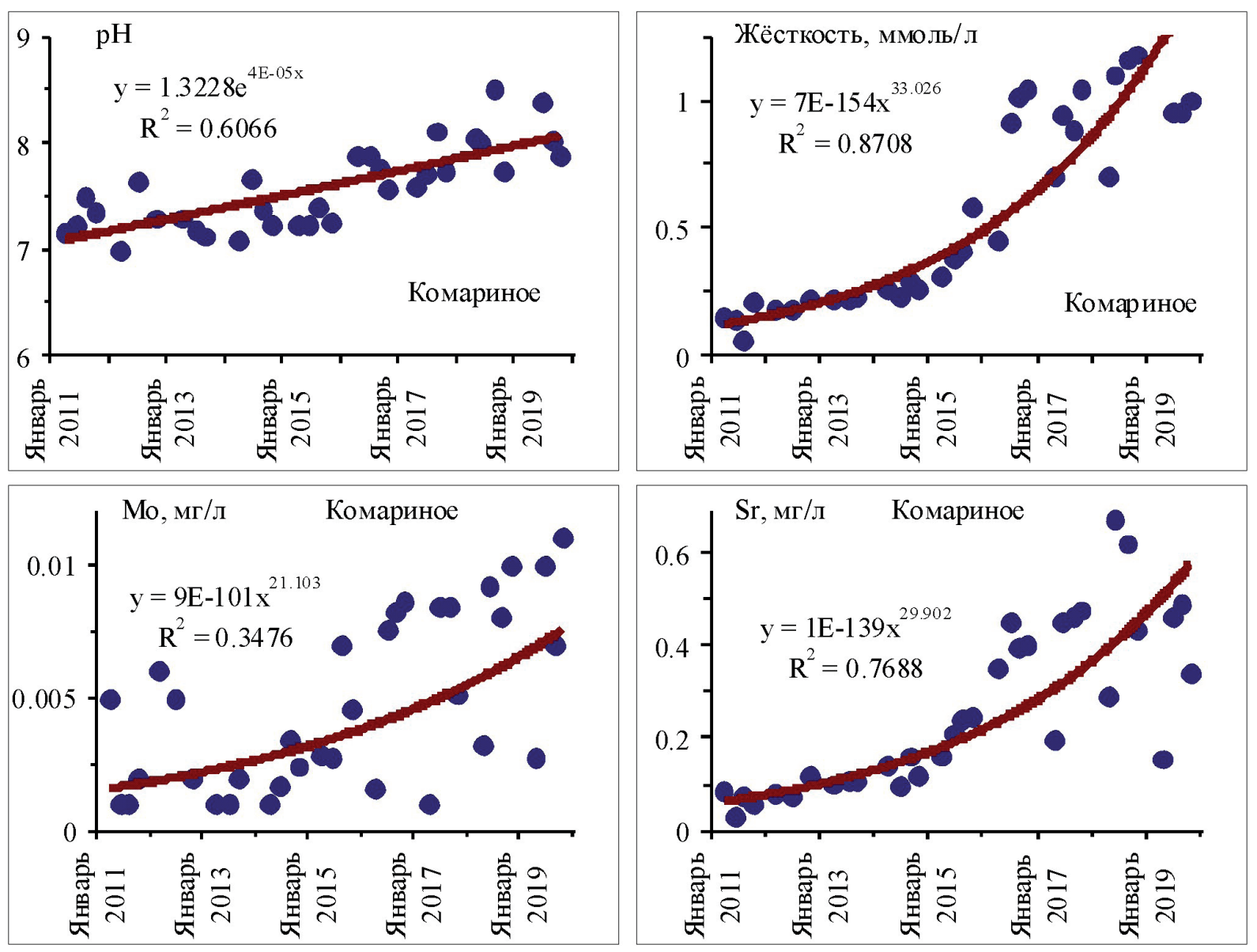

Рис. 2. Динамика значений рН, жесткости и содержания Мо и $\mathrm{Sr}$ в воде оз. Комариное за 2011-2019 гг.

Fig. 2. Dynamics of pH, hardness and Mo and Sr content in the water of Lake Komarinoe for 2011-2019.

с контактированием вод со щелочными породами, содержащими щелочные и щелочноземельные металлы. Увеличение содержание щелочноземельных металлов привело к повышению жесткости воды оз. Комариное (рис. 2).

Минералы Мо молибденит $\mathrm{MoS}_{2}$ молибдит $\mathrm{MoO}_{3}$, вульфенит $\mathrm{PbMoO}_{4}$ и ферримолибдит $\mathrm{Fe}_{2}\left(\mathrm{MoO}_{4}\right)_{2} \cdot 8 \mathrm{H}_{2} \mathrm{O}$ распространены в Хибинском горном массиве достаточно широко (Сулименко и др., 2017). Условия нахождения молибденита детально охарактеризованы А.Н. Лабунцовым, которым в 1927 г. было открыто молибденитовое месторождение Тахтарвумчорр (Красоткин и др., 2005). Молибденит присутствует в пегматитах и мельтейгит-уртитах Хибинского горного массива. В природных водах, приуроченных к районам разработки хибинских апатит-нефелиновых месторождений, обнаружено присутствие Мо в количествах, значительно превышающих ПДК лин и др., 2008; Сулименко и др., 2017; Чукаева, Матвеева, 2018). В воде оз. Комариное содержание Мо увеличивается в последние годы и превышает ПДК

Главным рудным минералом месторождения Олений ручей является фторапатит $\left(\mathrm{Ca}_{5}\left(\mathrm{PO}_{4}\right)_{3} \mathrm{~F}\right)$, который при выветривании поставляет F в природные воды в повышенных концентрациях. В природных водах территорий, подверженных влиянию разработки апатит-нефелиновых месторождений, отмечены повышенные содержания F (Кашулин и др., 2008). В воде оз. Комариное содержание F вплотную приблизилось к величине ПДК рбхз $(0.75$ мг/л).

Для нефелиновых сиенитов Хибинского горного массива Sr является типоморфным элементом (Добровольский, 1972). За время проведения мониторинга установлено достоверное увеличение содержания Sr воде о3. Комариное и в последние годы оно превышает величину ПДК (рис. 2). В воде оз. Комариное зафиксировано увеличение содержания $\mathrm{Cu}$, превышающего значение ПДК 


\section{Выводы}

Таким образом, в результате проведения десятилетних мониторинговых исследований химического состава воды оз. Комариное с начала разработки апатит-нефелинового месторождения Олений ручей выявлена достоверная тенденция к увеличению величины $\mathrm{pH}$, минерализации, содержания главных ионов, нитрат-иона $\mathrm{NO}_{3}^{-}$, а также ряда микроэлементов $(\mathrm{Sr}, \mathrm{Cu}, \mathrm{Mo}, \mathrm{F})$, в несколько раз превышающих величину ПДК

Работа выполнена в рамках темы НИР №0226-2019-0045 и частично поддержана из средств гранта РФФИ (18-05-60125).

\section{Литература}

1. Даувальтер В.А., Даувальтер М.В. Состояние подземных вод Мончегорского района // Вестник Кольского научного центра РАН. 2010. № 3. С. 26-33.

2. Даувальтер В.А., Даувальтер М.В. Геоэкологическая оценка состояния природных вод в зоне влияния комбината «Североникель». Мурманск. Изд-во: МГТУ. 2014. 216 с.

3. Даувальтер В.А., Даувальтер М.В. Экологическое состояние подземных вод Восточного рудника АО «Апатит» // Труды Ферсмановской научной сессии ГИ КНЦ РАН. 2019. № 16. С. 131-135. Doi.org/10.31241/FNS.2019.16.027.

4. Даувальтер В.А., Кашулин Н.А. Влияние деятельности горно-металлургических предприятий на химический состав озера Имандра, Мурманская область // Биосфера. 2015. Т. 7. № 3. С. 295-314.

5. Добровольский В.В. Минералогия и ландшафтно-геохимическая характеристика четвертичных отложений Кольского полуострова // Материалы к геохимии ландшафтов Кольского полуострова. Москва. Изд-во: МГПИ. 1972. С. 3-51.

6. Кашулин Н.А., Денисов Д.Б., Сандимиров С.С., Даувальтер В.А., Кашулина Т.Г., Малиновский Д.Н., Вандыш О.И., Ильяшук Б.П., Кудрявцева Л.П. Антропогенные изменения водных систем Хибинского горного массива (Мурманская область). В 2 т. Апатиты. Изд-во: КНЦ РАН. 2008. Т. 1. 250 с., Т. 2. 282 с.

7. Кашулин Н.А., Сандимиров С.С., Даувальтер В.А., Кудрявцева Л.П., Терентьев П.М., Денисов Д.Б., Вандыш О.И., Валькова С.А. Аннотированные экологический каталог озер Мурманской области (Восточная часть. Бассейн Белого моря). В 2 ч. Апатиты. Изд-во: КНЦ РАН. 2012. Ч. 1. 221 с.

8. Красоткин И.С., Войтеховский Ю.Л, Лесков А.Л., Удобина В.С. Заброшенный молибденитовый рудник Тахтарвумчорр // Труды Ферсмановской научной сессии ГИ КНЦ РАН. 2005. № 2. С. 10-14.

9. Мироненко В.А., Мольский Е.В., Румынин В.Г. Изучение загрязнения подземных вод в горнодобывающих районах. Л.: Недра. 1988. 279 с.

10. Мироненко В.А., Мольский Е.В., Румынин В.Г. Горнопромышленная гидрогеология. Москва. Изд-во: Недра. 1989. 287 с.

11. Сулименко Л.П., Кошкина Л.Б., Мингалева Т.А., Светлов А.В., Некипелов Д.А., Макаров Д.В., Маслобоев В.А. Молибден в зоне гипергенеза Хибинского горного массива. Мурманск. Изд-во: МГТУ. 2017. 148 с.

12. Чукаева М.А., Матвеева В.А. Современное гидрохимическое состояние гидроэкосистем, находящихся под техническим влиянием АО «Апатит» // Водные ресурсы. 2018. Т. 45. № 6. С. 685-690. DOI: $10.1134 / \mathrm{S} 0321059618060044$ 